\title{
THE DISTRIBUTION OF METEOR MASSES
}

\author{
I. G. BROWNE, K. BULLOUGH, S. EVANS AND T. R. KAISER \\ Jodrell Bank Experimental Station, University of Manchester, England
}

Kaiser (1953) [1] has shown how it is possible, from statistical studies of radio echoes from meteor trails, to obtain values of the exponent $s$ in the assumed equation for the number of meteors $n(\alpha)$ of line density $\alpha$

$$
n\left(\alpha_{m}\right) d \alpha=\text { const. } \frac{d \alpha}{\alpha_{m}^{8}},
$$

where $\alpha_{m}$ is the maximum electron line density (number of electrons per $\mathrm{cm}$.) produced in the trail of a meteor. If the simple theories of the meteor ionization process are correct, $\alpha_{m}$ is proportional to the meteor mass $m$, so that from radio echo studies it should be possible to obtain a measure of the meteor mass distribution:

$$
n(m) \cdot d m=\text { const. } \frac{d m}{m^{s}},
$$

where $n(m)$ is the number of meteors with mass in the range from $m$ to $m+d m$.

This paper presents new work carried out during the last three years by three independent methods giving information about different magnitude ranges, namely:

$$
\begin{array}{ll}
\text { Mag. } M=+7,+3: \text { distribution of echo amplitudes, } \\
+2>M>0: & \text { distribution of echo durations, } \\
+7>M>+5: & \text { distribution of echo heights. }
\end{array}
$$

The table below shows weighted mean values for sporadic meteors and various meteor showers, together with visual results for comparison. The probable errors are indicated by the number of significant figures in the values of $s$. It can be seen that radio and visual results are in close agreement.

A value of $s=2$ corresponds to constant total meteoric mass per magnitude range. Values of $s$ greater than 2 correspond to distributions in which the mass per magnitude range increases with magnitude, and vice versa. 
It will be seen that for all showers, with the exception of the Arietids, $s$ is less than 2 for faint meteors, but greater than 2 for bright meteors, suggesting that the mass per magnitude range for these showers has a maximum value around $M=+3$.

Values of $s$ for sporadic and shower meteors

\begin{tabular}{|c|c|c|c|c|c|c|}
\hline Shower & $\begin{array}{c}\text { Visual } \\
\mathbf{M}=+\mathbf{I} 0\end{array}$ & $\begin{array}{c}\text { Radio } \\
\mathbf{M}=+7\end{array}$ & $\underset{7>M>5}{\text { Radio }}$ & $\begin{array}{c}\text { Radio } \\
\mathbf{M}=+3\end{array}$ & $\begin{array}{c}\text { Radio } \\
2>M>0\end{array}$ & $\begin{array}{c}\text { Visual } \\
M<+3\end{array}$ \\
\hline Sporadic & $2 \cdot 0^{1,2}$ & I.98 & - & $2 \cdot 4$ & - & $2 \cdot 0^{1,2}$ \\
\hline Quadrantid & 一 & - & $x \cdot 78$ & - & $\mathrm{I} \cdot 8 *$ & $2 \cdot 5^{2}$ \\
\hline Perseid & - & $\mathbf{I} \cdot 38$ & $\mathrm{I} \cdot 59$ & $2 \cdot 0$ & $2 \cdot 0$ & $2 \cdot 1^{2,8}$ \\
\hline Arietid & - & - & $2 \cdot 7$ & - & $\mathrm{I} \cdot 8^{*}$ & - \\
\hline Geminid & - & I.45 & $1 \cdot 62$ & $2 \cdot 24$ & $2 \cdot 3$ & $2 \cdot 3^{2}$ \\
\hline
\end{tabular}

- These values are lower limits to $s$.

1 Watson (1941)[2].

2 Levin (1955)[3].

3 Mean value from analysis of measurements by Öpik (1922)[4], Levin (1955)[3], Kresak and Vozarova (1953)[5], Hruška (1954)[6] and Ceplecha (1952)[7].

Detailed results, including a discussion of the variation of $s$ with solar longitude during the Geminid and Perseid showers, are being published elsewhere (Browne, Bullough, Evans and Kaiser, I956) [8].

\section{REFERENGES}

[1] Kaiser, T. R. Advances in Physics (London), 2, 495, 1953.

[2] Watson, F. Between the Planets, Blakiston, I94I.

[3] Levin, B. J. Meteors (ed. Kaiser, T. R.), Pergamon Press, p. I31, 1955.

[4] Öpik, E. J. Publ. Astr. Obs. Tartu, 25, no. 4 (Quoted by Lovell, A. C. B. Meteor Astronomy, Oxford, 1954, p. 384), 1922.

[5] Kresak, L. and Vozarova, N. Bull. Astr. Inst. Czech. 4, I39, 1953.

[6] Hruška, A. Bull. Astr. Inst. Czech. 5, I3, 1954.

[7] Ceplecha, Z. Bull. Astr. Inst. Czech. 3, 65, 1952.

[8] Browne, I. G., Bullough, K., Evans, S. and Kaiser, T. R. Proc. Phys. Soc. B, 69, 83, 1956.

\section{Discussion}

Whipple: Bowen's rainfall theory should require many more weak meteors than suggested by Browne's results.

Browne: Indeed, by extrapolation to the roth magnitude one would expect the showers to be hardly visible against the sporadic background 